\title{
ENERGY INTEGRATION: GREEN FUTURE FOR LATE-LIFE OFFSHORE OIL AND GAS ASSETS
}

\author{
Nguyen Thu Huong', Nguyen Thi Thanh Le ${ }^{2}$ \\ 'Vietnam Petroleum Institute \\ ${ }^{2}$ Ministry of Industry and Trade \\ Email: huongnt@vpi.pvn.vn \\ https://doi.org/10.47800/PVJ.2021.10-06
}

\section{Summary}

In recent years, the oil and gas industry has been facing objections from a public greatly concerned with the severe environmental impact caused by fossil fuels and their infrastructures, and strong demands from policy makers seeking to meet decarbonisation goals. Amidst a global energy transition, the future demand, finance, and social responsibilities of oil and gas companies are increasingly in question. One of the biggest problems of the industry is what are the "green" solutions for the late-life offshore oil and gas assets. Energy integration with reusing or repurposing oil and gas assets for new technologies could be a worthwhile investment strategy helping reduce carbon emission from oil and gas production as well as accelerating carbon capture and storage (CCS) and green hydrogen development to support the global decarbonisation. According to research, the late-life offshore oil and gas assets play an important role in energy integration while helping to have more opportunities to develop the new technologies that are in the early stages of development with high capex, necessary to make them more economically attractive and facilitate maximum energy integration. Reusing or repurposing oil and gas infrastructure can lead to $30 \%$ capex saving and million tons of $\mathrm{CO}_{2}$ pa emission reductions.

In this paper, potential concepts of energy integration for offshore oil and gas assets are introduced, and some lessons learned and implications for reusing or repurposing late-life offshore assets for Vietnam are also presented.

Key words: Energy integration, late-life offshore oil and gas assets, electrification, green hydrogen, carbon capture and storage.

\section{Introduction}

After years of production, the oil and gas industry is facing an increasing demand for decommissioning which requires large costs and negatively affects the surrounding environment. Though worldwide estimates vary greatly, on average, decommissioning (decom) a complete platform may cost USD 15 million to USD 20 million in shallow waters (such as in the Gulf of Mexico), about GBP 30 million (USD 40 million) for small platforms, and GBP 200 million (USD 269 million) for large structures in deep waters (such as in the UK North Sea) [1]. According to Rystad Energy [2], the total value of the global pool of decom projects that will accumulate through 2024 could reach USD 42 billion, dominated by the UK North Sea. Besides, post-decom environment impacts are also of

Date of receipt: 30/8/2021. Date of review and editing: 30/8 - 30/9/2021. Date of approval: $7 / 10 / 2021$. great concern since a typical eight-leg structure provides a home for 12,000 to 14,000 fishes, and a typical four-leg structure provides 2 to 3 acres of habitat for hundreds of marine species, according to a study by the Coastal Marine Institute [3]. Therefore, one of the critical issues in the oil and gas industry is how to reduce the decom cost and protect the environment.

Conventionally, late-life offshore oil and gas assets must be decommissioned if they cannot work longer or be reused/repurposed. If the scrap steel market is stable and developed, contractors will get scrap revenue from the sale [4]. Otherwise, the scrap yards will charge the contractors to unload steel platforms [5]. Operating contractors are responsible for executing safe and environmentally sound decommissioning when operations cease. Nevertheless, almost all scrapping yards are on beaches so pollutants can cause serious environmental harm with long-term effects for occupational, public, and environmental health [4]. A "green" solution for offshore oil and gas assets is 
the best solution to deal with challenges of decarbonisation and decommissioning.

In recent years, international organisations (such as WEC, Nexstep, and North Sea Energy) and countries (such as Norway, UK, and the Netherlands) have been appreciating the role of offshore oil and gas assets in energy integration. By sharing infrastructure, the levelised costs of new technologies will reduce and promote the realisation of the ideas. In the WEC North Sea Conference in January 2017, market parties considered electrification, Power-to-gas (PtG), and carbon capture and storage the most potential technologies. Electrified platforms mean that energy is consumed at sea rather than transport to shore; PtG technologies enable energy storage and efficient transportation to shore; and CCS technologies reduce greenhouse gas emission [6 - 8]. With PtG technology, surplus electricity produced at offshore wind farms could be converted into hydrogen, methane, or other gases, and transported to shore using already existing pipelines.

What do you consider most valuable and realistic for the re-use of assets?

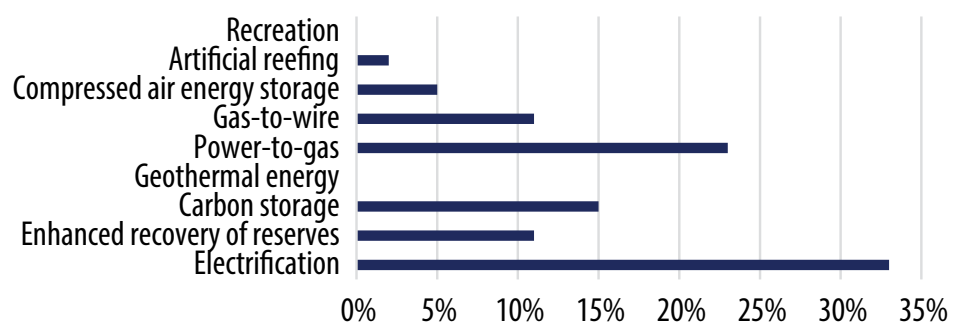

What do you consider the most inspiring option for re-use of assets?

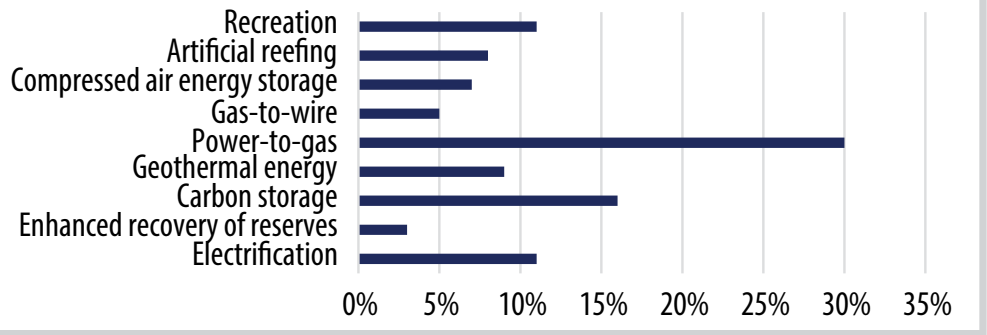

Figure 1. Opinion of market parties on prolonged and re-use options [6].

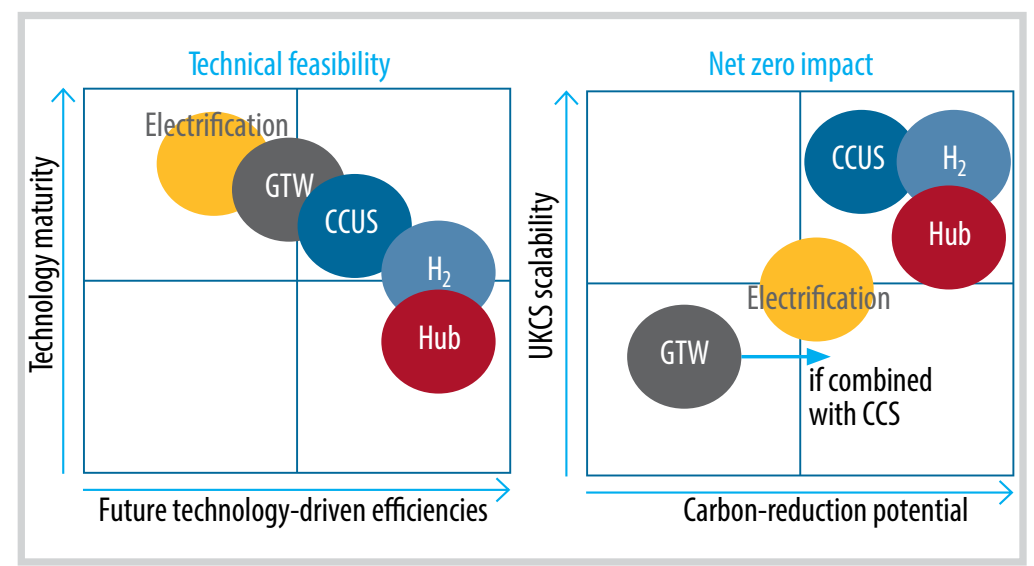

Figure 2. Technology screening for five concepts in the UK [9].
In which, green hydrogen is the most viable option of PtG technologies and is being studied and tested by some countries such as the UK and the Netherlands.

Similarly, the Oil and Gas Authority (OGA) has pointed out that energy integration between oil and gas and renewable energy is the main solution to achieve net-zero emission by $2050[9,10]$. The North Sea provides several energy options which can all be integrated: wind farms, oil and gas platforms, tidal and wave energy, green hydrogen, floating solar, OTEC (ocean thermal energy conversion). Offshore oil and gas assets can play an important role, for example in the storage of $\mathrm{CO}_{2}$, and the production of hydrogen and renewable energy [11]. The OGA forecasted that oil and gas will remain an important part of the energy mix for the foreseeable future, and the oil and gas industry will go much further in reducing its carbon footprint from operations. A more integrated offshore energy sector, including closer links between oil and gas and the offshore renewables, will be vital to accelerate the energy transition [9]. Five potential concepts that OGA mentioned to deal with energy transition include Electrification, Gas-to-wire (GtW), CCUS/CCS, Hydrogen, and Energy Hubs.

According to WEC, value is created through the delay of decommissioning costs ( EUR 1 billion). Cost reduction for CCS could save EUR 14 billion over the 2017 - 2050 period.CCS as well as electrification of existing O\&G platforms contribute to $\mathrm{CO}_{2}$ reduction. If $25 \%$ of platforms would be electrified, then $4 \mathrm{Mt} \mathrm{CO}$ could be avoided over the 2017 2050 period. For CCS technology, based on a "medium" roll-out scenario, $\mathrm{CO}_{2}$ emissions could be reduced by approximately $\sim 1,200$ Mt in the 2017 - 2050 period [6]. According to Nexstep, offshore asset reuse will reduce the decommissioning cost in the Netherlands by $30 \%$ [11]. However, studies show that only $10 \%$ of the platforms in the Netherlands are suitable for reuse. 


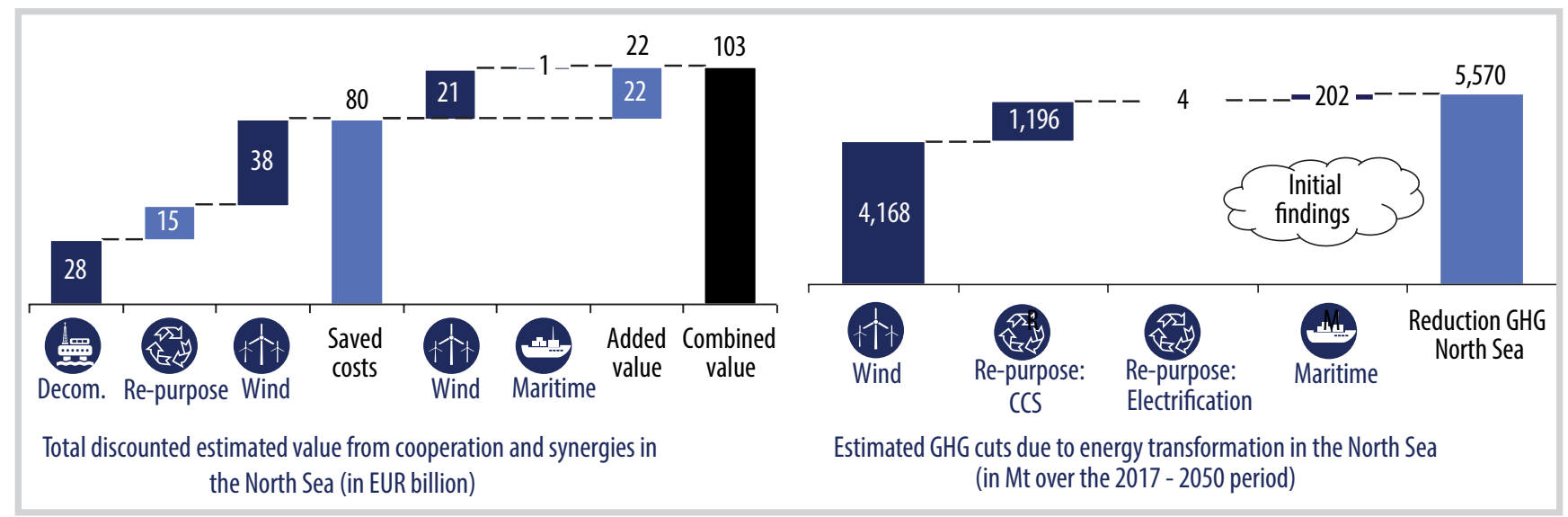

Figure 3. Benefits of repurposing old $0 \& G$ assets in the North Sea [6].

Table 1. Three options for offshore platform electrification in the North Sea [9, 12]

\begin{tabular}{|c|l|c|c|}
\hline \multicolumn{1}{c}{$\begin{array}{c}\text { Option 1 } \\
\text { (Power from shore) }\end{array}$} & \multicolumn{1}{c}{$\begin{array}{c}\text { Option 2 } \\
\text { (Power from interconnectors) }\end{array}$} & $\begin{array}{c}\text { Option 3 } \\
\text { (Power from wind farms) }\end{array}$ \\
\hline \begin{tabular}{l|l} 
A platform can be connected via a cable to the \\
onshore grid
\end{tabular} & $\begin{array}{c}\text { Platform uses power from interconnectors } \\
\text { Platform uses power from wind farms }\end{array}$ \\
\hline & & Power supply continuity & \\
\hline
\end{tabular}

As can be seen, electrification, hydrogen, and CCS are the potential concepts for energy integration. However, these technologies are still at a very early stage of development and therefore hurdles exist in all areas. In many cases, there are no example business cases to learn from and often technologies are not yet available, or not designed for offshore use [6]. At present, there are only a few pilot projects in Norway and the Netherlands, and research projects in the UK. The next part presents the status of these potential concepts of energy integration for offshore oil and gas assets.

\section{Potential concepts of energy integration for offshore oil and gas assets}

\subsection{Electrification}

Electrification of oil and gas platforms is a way in which energy can be consumed efficiently at sea [6]. This idea will help increase energy efficiency and cut down a large amount of carbon emissions. The offshore oil and gas platforms are using gas- or diesel-powered generators to supply their own electricity needs. Due to the space and weight limitations of the platform, these generators are designed with minimum power generation facilities. This means that the energy conversion efficiency rate is low and carbon emissions relatively high. This kind of offshore generator emits more $\mathrm{CO}_{2}$ than an onshore generator. To reduce carbon emissions of offshore oil and gas activities, electrification is considered the optimal solution.

In addition, old platforms can be converted into electrical substations for floating offshore wind farms at the end of field life. The conversion will be more advantageous if the offshore platform is electrified. Electrification for offshore platforms is still in the early research and implementation stages. In the North Sea, three electrification options for offshore oil and gas platforms are suggested. 


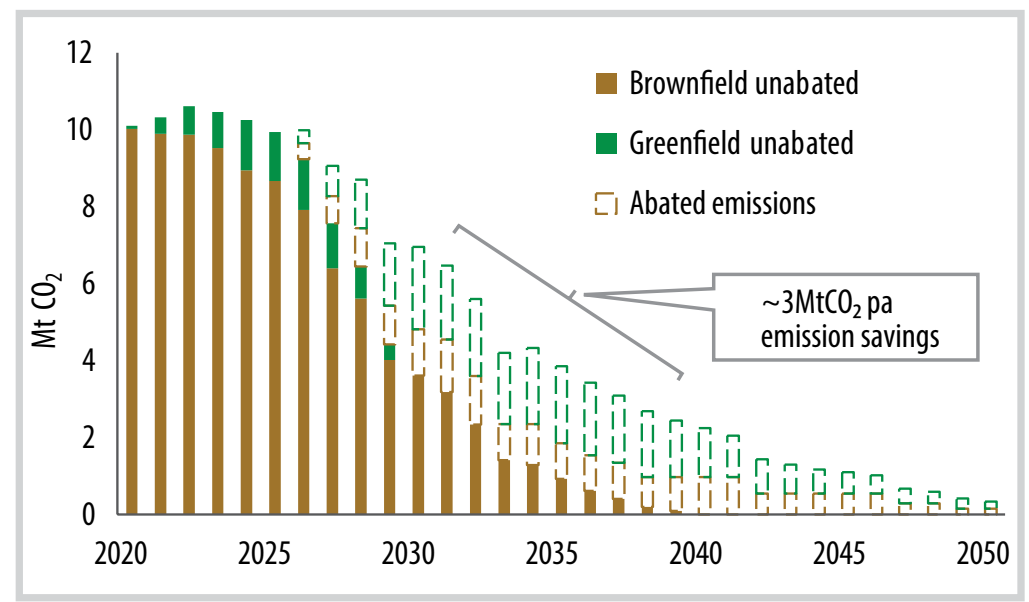

Figure 4. Potential emission reduction from 0\& G power generation [10].

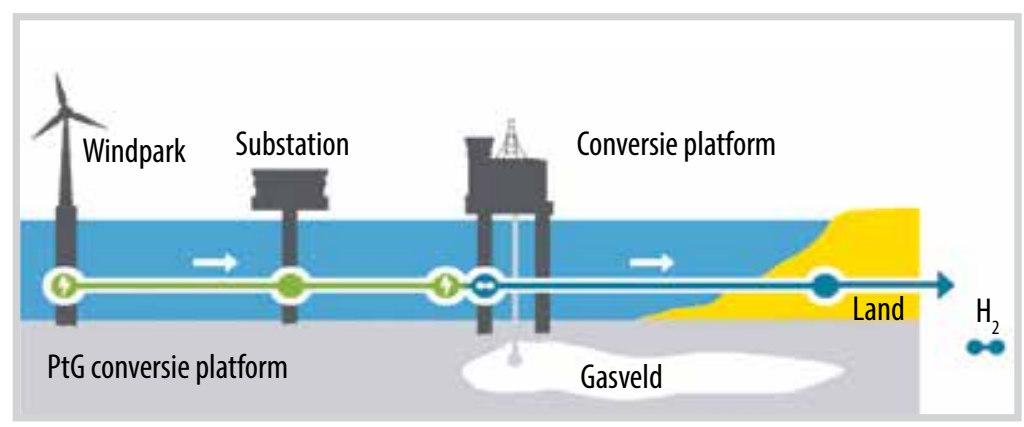

Figure 5. Schematic overview of conversion to green hydrogen [13].

In the Netherlands, the transmission system operator (TSO) TenneT is the designated offshore grid operator with the statutory task to create a dedicated offshore grid to connect offshore wind energy farms to the onshore grids. For many platforms further offshore, it would significantly reduce their costs of obtaining a grid connection if it would be possible to tie in and connect to an offshore platform [12]. Besides, the North Sea Energy program is researching the potential connection between offshore platforms and wind farms.

Electrification can lead to lower operating costs for platform operators and eliminate emissions from traditional generators. According to OGA, the oil and gas industry could significantly reduce GHG emission (by approximately 2 - $3 \mathrm{MtCO}_{2}$ e pa) by sourcing power for its UKCS platform either from the shore or from offshore renewables. While brownfield electrification projects could face high Capex, which could be significantly reduced through synergies with wind power (could lead to breakeven), while greenfield (new assets) electrification can add value through Capex savings to offset power connection cost $(B C R>1)$ [10].

It is obvious that electrification is an essential response by the $O \& G$ industry to net-zero emission. Reducing emissions will be an urgent mission when IOCs and NOCs are dealing with energy transition. Sourcing electricity for O\&G directly from offshore renewables helps reduce project lifecycle costs. Furthermore, lower operating costs can extend the lifetime of the field and increase the opportunity to utilise the platform for other future potential purposes, such as offshore hydrogen production.

\subsection{Green hydrogen}

Green hydrogen is produced using renewable energy and electrolysis to split water. With PtG technology, surplus electricity produced at offshore wind farms could be converted into hydrogen and transported to shore using already existing pipelines [6]. This technology is an efficient solution for storing and transporting energy to shore. The existing offshore pipelines could be put into a new production use instead of installation of new offshore power cables. Because the transportation capacity of pipelines is much larger than that of power cables, transportation losses are less, and grid stability is not a concern. However, quantitative evaluation of this idea is difficult because limited real-life experience is available. The offshore hydrogen production model is being studied and tested by some countries, such as the UK and the Netherlands.

In the UK, the results of OGA research show that offshore green hydrogen generation may also be placed offshore, potentially repurposing legacy oil and gas platforms. Depending on distances from shore, this may provide efficient energy transmission [9]. The offshore green hydrogen option consists of three steps: (1) wind-powered electrolysis on offshore platforms; (2) hydrogen storage in abandoned fields or salt caverns; (3) hydrogen transportation with re-used pipelines. As can be seen, all offshore oil and gas assets, such as platforms, pipelines, and reservoirs, are fully utilised in the hydrogen production process. However, this study also indicates that green hydrogen is not economically attractive today ( $B C R \sim 0.7)$ due to high electrolysed costs. OGA expects that these costs will be reduced to achieve project breakeven by technology improvements in this decade [10].

In the Netherlands, North Sea Energy also shows that power can be converted into hydrogen using electrolysis [13]. Electrical 


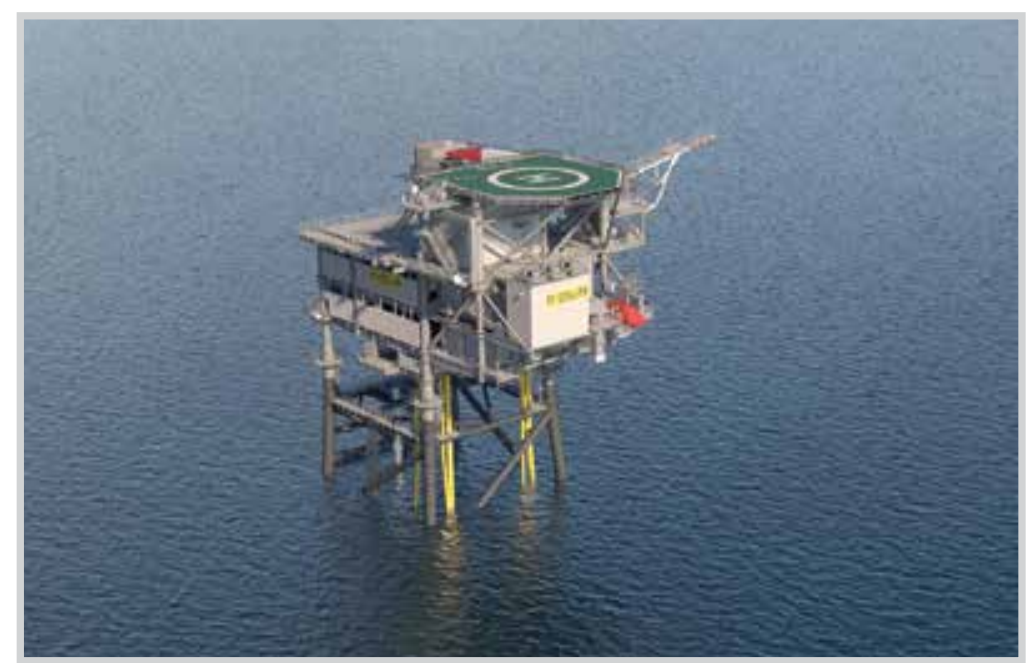

Figure 6. Pilot PosHydon on Neptune Energy's Q13a-A platform [15].

- Type: PEM electrolyser

- Nr. of Cell stacks: 1

- Input power: $\quad 1 \mathrm{MW}$

- Water consumption: $300 \mathrm{l} / \mathrm{h}$

- Hydrogen flow: $\quad 200 \mathrm{Nm}^{3} / \mathrm{h}$

- Hydrogen purity: $\quad 99.998 \%$

- Outlet pressure: $30 \mathrm{barg}$

- Footprint: $\quad 40 \mathrm{ft}$ container

-Weight: $\quad$ lifting weight of $<20$ tons

(perhaps requiring $40 \mathrm{ft}$ container to be broken down in smaller units)
Polymer electrolyte membrane electrolysis

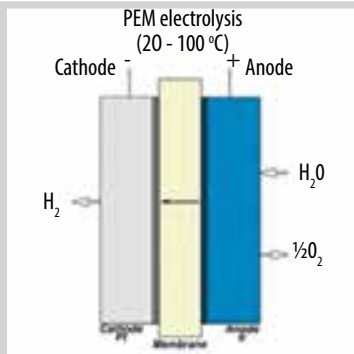

$\mathrm{H}_{2} \mathrm{O} \rightarrow 2 \mathrm{H}^{+}+1 / 2 \mathrm{O}_{2}+2 \mathrm{e}^{-} \quad$ Anode $2 \mathrm{H}^{+}+2 \mathrm{e}^{-} \rightarrow \mathrm{H}_{2} \quad$ Cathode $\mathrm{H}_{2} \mathrm{O} \rightarrow \mathrm{H}_{2}+1 / 2 \mathrm{O}_{2} \quad$ Total Reaction Diagram of PEM electrolysis reactions
Figure 7. Assumption for PosHydon project [16].

Table 2. Overview of technical characteristics of Neptune Energy's Q13a-A [16]

\begin{tabular}{|c|c|}
\hline Location & $52^{\circ} 11^{\prime} 30.84^{\prime \prime} \mathrm{N} ; 4^{\circ} 08^{\prime} 14.66^{\prime \prime} \mathrm{E}$ \\
\hline Distance from onshore & $\begin{array}{l}13.4 \text { km (from Scheveningen, Hague); } 94.6 \text { km } \\
\text { (from Den Helder) }\end{array}$ \\
\hline Water depth (WD) & $20 \mathrm{~m}$ \\
\hline Installation & 2013 \\
\hline Platform details & $\begin{array}{l}\text { Normally unmanned, zero emission to air and sea } \\
\text { Electrification: powered from shore } \\
\text { Main deck area: } 400 \mathrm{~m}^{2} \text {; Deck load: } 1,680 \mathrm{~kg} / \mathrm{m}^{2}\end{array}$ \\
\hline Current production & $4,000 \mathrm{~b} / \mathrm{d}$ oil; $40,000 \mathrm{Nm}^{3} / \mathrm{d}$ gas ( $\left.400 \mathrm{Nm} 3 / \mathrm{hr} @ 35 \mathrm{barg}\right)$ \\
\hline Pipeline pressure & $\sim 32$ barg \\
\hline Hydrogen flow & 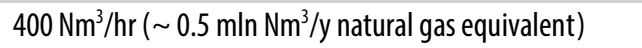 \\
\hline
\end{tabular}

energy derived from wind farms is transported to an offshore platform to produce hydrogen. The electrical energy (electrons) is converted into chemical energy in the form of gas (molecules). Seawater is desalinated first and filtered into demi water, which will be used for electrolysis. This water is then electrolysed into hydrogen and oxygen gas. From the mining rigs, hydrogen is compressed and transported ashore through new or existing pipelines. According to North Sea Energy, the benefit of this idea extends the economic lifetime of offshore oil and gas assets, saves costs on offshore cabling systems, and improves efficiency in storage and transportation of energy to shore.

Currently, this idea has been investigated and tested through the PosHydon project in the Netherlands. The PosHydon project is the world's first offshore green hydrogen project on an operational oil and gas platform, using a facility in the Dutch North Sea. It is one of the actions of the Dutch government to promote offshore energy integration to achieve the goal of reducing $95 \%$ carbon emission by 2050. On 22 July, 2021, this project received EUR 3.6 million (USD 4.25 million) subsidy from the Netherlands Enterprise Agency [14]. The cost of the pilot project is in the region of EUR 10 million (USD 11.58 million) in a 2-year duration pilot (ending by the end of 2023). PosHydon, which will be hosted on Neptune Energy's Q13a-A platform, $13 \mathrm{~km}$ off the coast of Scheveningen in the Hague, aims to validate the integration of offshore wind, gas, and hydrogen.

The PosHydon project is a pilot project to produce green hydrogen using proton exchange membrane (PEM) electrolysis technology. In this method, the electrolyte is an acidic polymer membrane that allows the exchange of protons $\left(\mathrm{H}^{+}\right)$. At the anode, water is oxidised to $\mathrm{O}_{2}$ and releases protons that flow across the membrane and are reduced at the cathode to form $\mathrm{H}_{2}$. The $1 \mathrm{MW}$ electrolyser will produce a maximum of $400 \mathrm{~kg}$ of green hydrogen per day.

Green hydrogen production will take place on the operating Neptune Q13a-A platform. This platform has been electrified and is a zero-carbon platform $(16,000$ tons of $\mathrm{CO}_{2}$ /year). An old sewage pipe under the sea is reused to carry an electrical cable connecting the Hague's electricity grid to the platform. Thus, during this test phase, hydrogen is produced by using onshore 
electricity. In the future, the platform can be directly powered by offshore wind. Green hydrogen products will be mixed with extracted gas and then transported to shore through the existing gas pipeline system. The future operation and maintenance costs can be shared between hydrogen and gas producers. The project studies how hydrogen can be mixed with natural gas in existing gas pipelines, testing the best percentages for onshore processing [17], and specifying the mixing percentage of hydrogen in the natural gas suitable for the onshore distribution grid [18]. Here are some key technical characteristics of the Q13a-A platform used for testing offshore green hydrogen production and transportation.

According to the implementation progress, the PosHydon project is onshore electrolyser testing and offshore installation, and ready to start up in Q4 2021. If the project is successfully implemented, it will be a good lesson for countries in the North Sea region and the world. Furthermore, some platforms and pipelines could be given a second life in the energy transition and be used for power conversion and transportation of green hydrogen [19].

\subsection{Carbon capture and storage (CCS)}

The CCS technology will provide an opportunity to reuse/ repurpose offshore oil and gas assets to store $\mathrm{CO}_{2}$ under the empty oil or gas fields. $\mathrm{CO}_{2}$ will be captured and transported from the shore through new or existing pipelines. Then $\mathrm{CO}_{2}$ is slowly

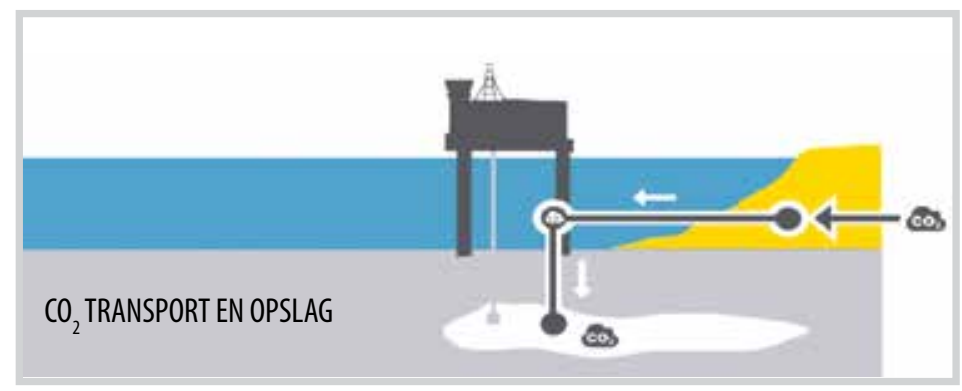

Figure 8. Schematic overview of CCS technology [13].
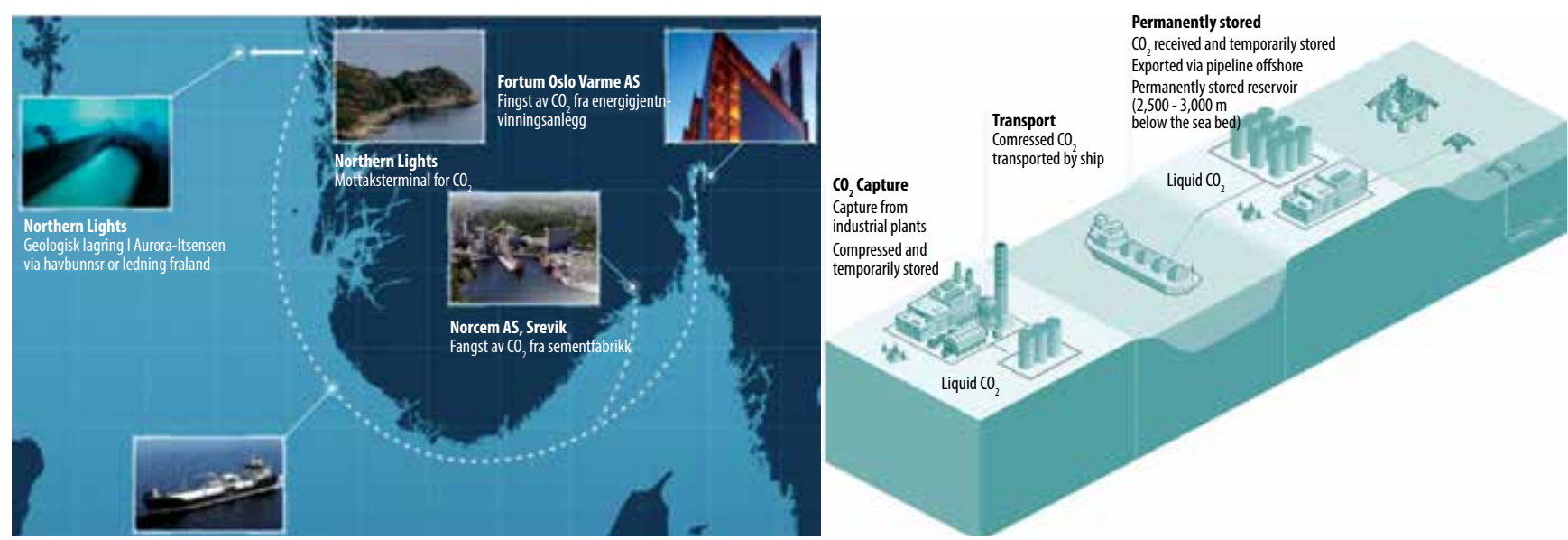

injected into the reservoir, which will increase the pressure in the reservoir. Injection will continue until the reservoir's pressure almost reaches the same level as the original natural gas pressure. The reservoir pressure will be kept at a lower level than the original one, to ensure the natural geological closure of the reservoir [13]. If the platform is already electrified, the offshore compression could easily be installed. If the platform is applying the $\mathrm{CO}_{2}$-EOR method to prolong the field lifetime, the infrastructure is very convenient to develop CCS technology. Almost all offshore oil and gas assets, such as platforms, pipelines, wells, and reservoirs, will be utilised to reduce costs and promote the offshore CCS technology.

According to WEC, the CCS projects in the North Sea have a potential value of EUR 14.4 billion over the period from 2020 to 2050. This value includes the cost savings resulting from the reduction in CCS costs from EUR 70/ton of $\mathrm{CO}_{2}$ in 2017 to EUR 45/ton of $\mathrm{CO}_{2}$ in 2030. From 2020 to 2030, the annual $\mathrm{CO}_{2}$ storage will increase linearly from $4 \mathrm{Mt}$ to $46 \mathrm{Mt}$ storage per year and remain constant at 46 Mt per year from 2030 [6].

In the North Sea, Norway and the UK are two countries that are studying the possibility of developing CCS when taking advantage of offshore oil and gas assets. Below is a summary of the research results of these two countries.

\section{Norway}

Norway has a long history of carbon capture and storage from the world's first offshore CCS project "Sleipner" in 1996. The Norwegian

Figure 9. The Norwegian full-scale CCS project Longship [22, 23]. 
government considers CCS an important solution to achieve net zero emissions by 2050. Since 2005, Gassnova, a stateowned enterprise under the Norwegian Ministry of Oil and Energy, has promoted technological development, reduced costs, and enabled CCS development projects through knowledge sharing and technology transfer with partners [20]. In 2016, the results of a feasibility study on CCS solutions conducted by Statoil were released by the government. This study demonstrated the feasibility of combining components that make up the value chain and can be realised into a fullscale CCS project. Gassnova was assigned to represent the Norwegian government to further develop this idea. In December 2020, the Norwegian government made a funding decision and named the project Longship [21]. The project's ambition is to be able to store 1.5 million tons of $\mathrm{CO}_{2}$ per year. So far, this is the largest project in the history of Norway with a total cost of about USD 2.83 billion (USD 1.93 billion investment cost and a 10-year operating cost of USD 0.9 billion) which the

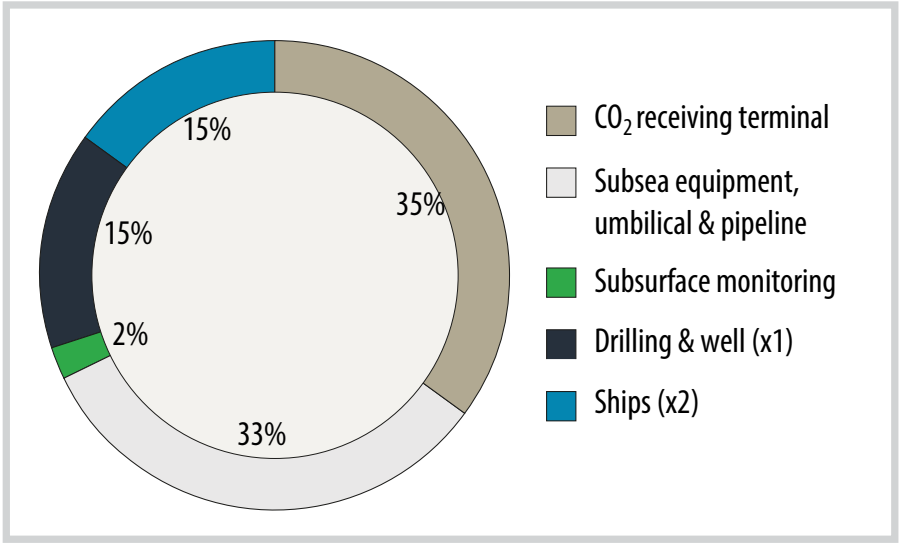

Figure 10. Estimated investment cost spread across the physical elements of the transport and storage facilities [24].
Norwegian government is expected to provide USD 1.89 billion [22].

The Longship project consists of three main parts:

- $\mathrm{CO}_{2}$ capture at Norcem Cement Plant (belonging to Heidelberg Group) in Brevik;

- $\mathrm{CO}_{2}$ capture at the Fortum Oslo Waste-toEnergy Plant in Oslo;

- Combined transportation and storage solution, managed by Northern Lights JV DA.

The Northern Lights JV was launched in March 2021 as a joint venture between Equinor, Shell, and Total. The Northern Lights project, which is part of the Longship project, is responsible for the transport of $\mathrm{CO}_{2}$ by ships and the permanent storage of $\mathrm{CO}_{2}$ in reservoirs located 2.5 - $3 \mathrm{~km}$ deep on the seabed. It is expected that phase 1 of this project will operate in mid-2024 with a capacity of 1.5 million tons of $\mathrm{CO}_{2} /$ year.

According to Gassnova, $\mathrm{CO}_{2}$ can be stored forever under depleted oil and gas reservoirs and salt aquifers. Offshore oil and gas assets have an important role in the CCS process. The existing pipeline transports carbon from shore to the compression station, are converted by platform, to compress $\mathrm{CO}_{2}$ into depleted reservoirs. In 2020, Gassnova expected the allocation of investment costs for carbon transport and storage as follows:

If late-life offshore oil and gas assets can be used

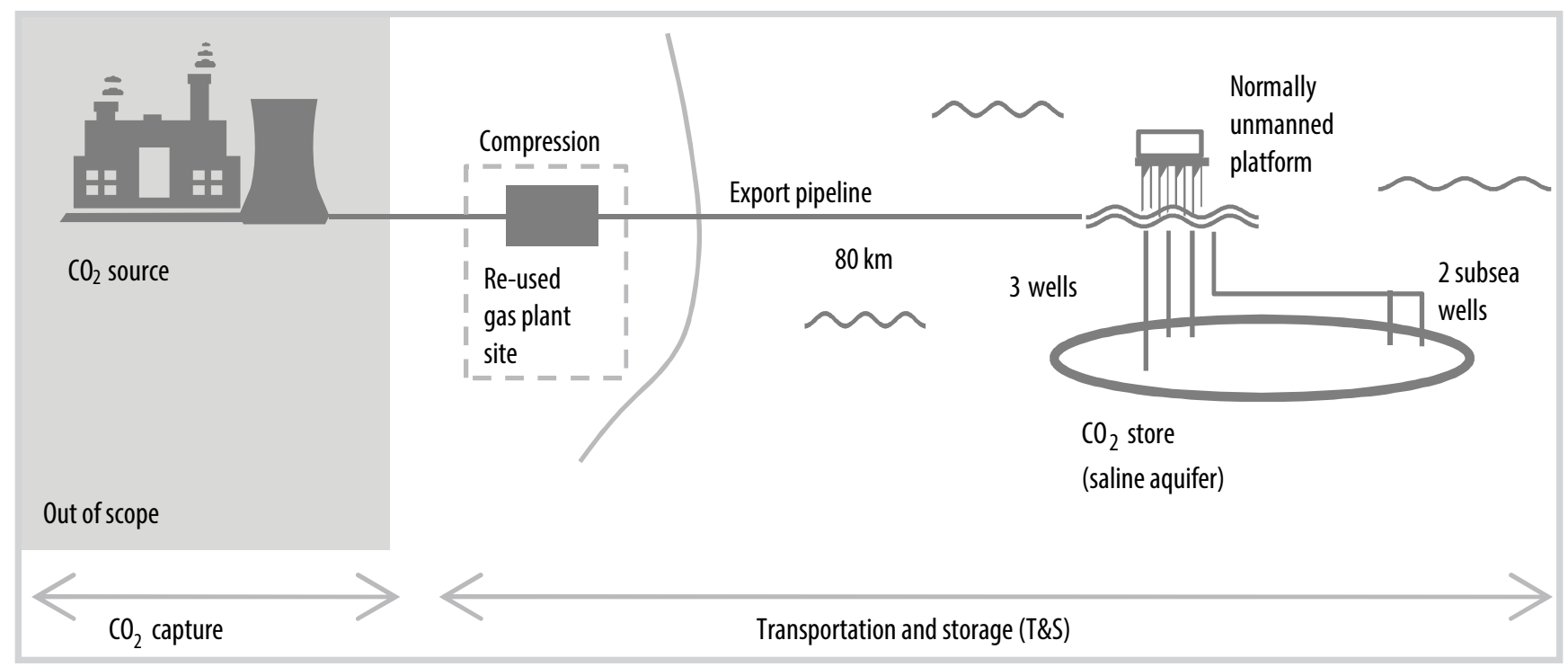

Figure 11. Notional CCS project [10]. 
for carbon transport and storage, there is potential for investment savings at this stage.

\section{UK}

The UK also considers CCS technology as an important solution to achieve net-zero emissions by 2050. To achieve this ambition, OGA has proposed a scenario of building CCS by 2050. Accordingly, OGA expects to increase annual compression capacity at a rapid growth rate from 5 million tons of $\mathrm{CO}_{2}$ /year in 2025 to 69 million tons of $\mathrm{CO}_{2}$ /year by 2040, and 130 million tons of $\mathrm{CO}_{2}$ /year by 2050.

Under the OGA scenario, offshore oil and gas assets will be utilised in $\mathrm{CO}_{2}$ transport and storage:

- $\mathrm{CO}_{2}$ transport: Onshore gas plants can be converted into $\mathrm{CO}_{2}$ compressor plants, taking advantage of the existing pipeline system from gas plants to transport $\mathrm{CO}_{2}$ to compressed air points. It is assumed that this pipeline is about $80 \mathrm{~km}$ long and 20" in diameter.

- $\mathrm{CO}_{2}$ storage: Existing platforms and wells can be used to compress $\mathrm{CO}_{2}$ into empty reservoirs.

The OGA research results indicate that reuse of existing oil and gas infrastructure can lead to $20-30 \%$ capex savings, thus the transportation and storage costs around GBP 12 - 30/ton of $\mathrm{CO}_{2}$ (USD 16 - 40/ton of $\mathrm{CO}_{2}$ ) could make CCS economically attractive to help decarbonise in the UK [10].

\subsection{Lesson learned for late-life offshore oil and gas assets in Vietnam}

Obviously, offshore oil and gas assets play an important role in energy integration which can help reduce production emission for the oil and gas industry, as well as accelerate the progress of CCS and green hydrogen in support of decarbonisation. Firstly, platform electrification could reduce emissions on oil and gas structures by using offshore electricity generated from wind farms. Secondly, surplus electricity produced at offshore wind farms could be converted into green hydrogen at the platforms and transported to shore by existing pipelines. Finally, $\mathrm{CO}_{2}$ is transported by pipeline, and injected into depleted offshore oil and gas fields.

However, these new technologies are in the early stages of development with high capex, so it is necessary to maximise the utilisation of energy integration. By sharing offshore infrastructures, these new technologies have more opportunities to develop in the future. Due to the shortage of example business cases, it is difficult to generalise the technical requirements for offshore oil and gas assets. Based on existing documents, the offshore oil and gas assets in the North Sea often have the following technical characteristics:

- Water depth (WD): often in shallow water

+ 20 m: Neptune Energy's Q13a-A in PosHydon project [16];

+ $29.6 \mathrm{~m}$ : project IJVERGAS [25];

+ Less than $50 \mathrm{~m}: 10 \%$ of platforms in the Netherlands that have been reused by Nexstep $[11,26]$.

- Distance from shore:

+ 51 km: Neptune Energy's Q13a-A in PosHydon project [16];

+ 80 km: UK CCS development scenario [10].

- Type of platform: Mostly fixed platforms.

- Diameters of pipelines: 20" [10], 24" and 36" [25].

Compared to the above-mentioned, Vietnamese offshore oil and gas assets have similar characteristics [27], specifically:

- Water depth (WD): All production projects are in shallow water.

- Distance from shore: Structures are located far from the shore, but the infrastructure allows easy connection to shore through offshore pipelines. The distance from onshore of main pipelines in Cuu Long basin, Nam Con Son basin, and Malay - Tho Chu basin is $110 \mathrm{~km}, 371 \mathrm{~km}$, and $298 \mathrm{~km}$, respectively.

- Type of platform: Mostly wellhead platforms (a kind of fixed platform), only one semi-submersible platform in Dai Hung field.

- Diameters of pipelines: $\sim 26^{\prime \prime}$ for main pipelines.

- Density of distribution: All production projects are concentrated in the 4 main basins: Cuu Long basin, Nam Con Son basin, Malay - Tho Chu basin, and Song Hong basin.

- Ability to connect to existing infrastructure: Pipelines are only connected internally in each basin.

- Oil/gas reservoirs: Offshore oil/gas reservoirs are connected to wellhead platforms. Therefore, CCS projects can reuse the offshore facilities to store $\mathrm{CO}_{2}$ in these empty reservoirs. 
- Ability to connect to offshore wind farms: According to draft Power Master Plan VIII [28], potential offshore wind plants will be located in the North, North Central, South Central, and Southern regions of Vietnam, corresponding to the Song Hong basin, Cuu Long basin, Nam Con Son basin, and Malay - Tho Chu basin. The potential offshore wind plants can be in more or less 50 m of water depth in the South, South Central, and North Central regions.

If preliminary assessment, Vietnam offshore facilities can research the potential connecting oil and gas assets and renewable energy instead of decommissioning, especially late-life offshore oil and gas assets in the South. However, not all oil and gas assets can be reused for new technologies. In the Netherlands, only $10 \%$ of platforms is suitable for reuse/repurpose, but it can lead to $30 \%$ capex savings and million tons of $\mathrm{CO}_{2}$ pa emission reductions [11], which is a great driving factor to develop the new technologies.

\section{Conclusion}

Energy integration is a green solution reusing or repurposing assets for new technologies, such as electrification, green hydrogen and CCS, or promoting synchronous development of technologies, sharing offshore infrastructure, and reducing infrastructure investment costs. The energy sector can start making unified decisions about how to deal with end-of-life offshore oil production facilities. The late-life offshore oil and gas assets will have a new life and play an important role in dealing with climate change and gradually achieving decarbonisation goals. Integrating late-life offshore oil and gas assets and other offshore energy farms could reduce the costs and make the new technologies more economically feasible.

According to the North Sea's case, the conversion of offshore oil and gas assets needs to have a longterm strategy and follow a roadmap. In which, three important milestones need to be achieved: (i) minimising carbon emissions in offshore oil and gas exploitation through electrification technology; (ii) energy transition, connection, and development of green hydrogen and CCS technologies; (iii) connecting all energy sources to reach the committed carbon emission reduction target.

In general, the Vietnamese offshore oil and gas assets have similar technical characteristics with those in the North Sea. Therefore, there is an opportunity to have a green future for late-life offshore oil and gas assets in Vietnam. To turn the ideas into reality, more detailed studies will be needed. The studies should be conducted as soon as possible because Vietnam will face the wave of decommissioning in the next decade.

\section{References}

[1] Rajesh Chhabara, "Offshore oil rigs: Can decommissioning ever be green?", Sustainable Business, 1/9/2009. [Online]. Available: https://www.reutersevents. com/sustainability/stakeholder-engagement/offshoreoil-rigs-can-decommissioning-ever-be-green.

[2] Rystad Energy, "Global oil \& gas decommissioning costs to total USD 42 billion through 2024, dominated by UK North Sea", 22/5/2020. [Online]. Available: https:// www.rystadenergy.com/newsevents/news/pressreleases/global-oil-gas-decommissioning-costs-to-total\$42-billion-through-2024-dominated-by-uk-north-sea/.

[3] Bureau of Satety and Environmental Enforcement (BSEE), "Rigs-to-reefs", 2021. [Online]. Available: https:// www.bsee.gov/what-we-do/environmental-compliance/ environmental-programs/rigs-to-reefs.

[4] NGO Shipbreaking Platform, "Recycling outlook: Decommissioning of North Sea floating oil \& gas units", Norway, 2019.

[5] ICF International and TSB Offshore, "Decommissioning methodology and cost evaluation", 2015.

[6] World Energy Council (WEC), "The North Sea opportunity", 2017.

[7] Rene Peters and Ewald Breunesse, "Prolonging life and re-purpose of oil and gas assets", World Energy Council, 2016. [Online]. Available: https://www. worldenergycouncil.nl/wp-content/uploads/2017/02/ WEC-repurpose-TNO-Shell-breakout-session.pdf

[8] Rene Peters, "A green use for old drilling platforms?", Energy World, 2019.

[9] OGA, "UKCS energy integration: Interim findings", 17/12/2019. [Online]. Available: https://www.ogauthority. co.uk/news-publications/publications/2019/ukcs-energyintegration-interim-findings/.

[10] OGA, "UKCS energy integration: Final report", 6/8/2020. [Online]. Available: https://www.ogauthority. co.uk/media/6625/ukcs_energy_integration_phase-ii_ report_website-version-final.pdf. 
[11] Nexstep, "Re-use \& decommissioning report: Innovation \& collaboration", 2020. [Online]. Available: https://www.nexstep.nl/wp-content/uploads/2020/07/ Re-use-decommissioning-rapport-2020-ENG_final.pdf

[12] North Sea Energy, "North Sea Energy II regulatory framework: Barriers or drivers for offshore system integration", 2018.

[13] Sytske Stuij and Suzan Tack, "North Sea Energy II: Strategic assessment of environmental impacts of offshore system integration options", North Sea Energy, 2018. [Online]. Available: https://north-sea-energy.eu/ static/ce06f2b63708efd85f33fbf216fbd28e/NSE2_D. D2_Strategic-Assessment-of-Environmental-Impacts-ofOffshore-system-Integration-Options-1.pdf.

[14] Sanja Pekic, "Netherlands grants PosHYdon offshore green hydrogen project", 22/7/2021. [Online]. Available: https://www.offshore-energy.biz/netherlandsgrants-poshydon-offshore-green-hydrogen-project/.

[15] Neptune Energy, "The world's first offshore green hydrogen plant", 2021. [Online]. Available: https:// www.neptuneenergy.com/esg/new-energy/poshydonhydrogen-pilot.

[16] Neptune Energy, "PosHYdon Pilot: Offshore green hydrogen", 2019. [Online]. Available: https:// www.neptuneenergy.com/esg/new-energy/poshydonhydrogen-pilot.

[17] Naomi Klinge, "Existing oil and gas infrastructure has potential in offshore green hydrogen", 19/8/2021. [Online]. Available: https://www.upstreamonline.com/ energy-transition/existing-oil-and-gas-infrastructurehas-potential-in-offshore-green-hydrogen/2-1-1054605.

[18] Chris Carpenter, "Offshore hydrogen production enables far offshore wind development", 23/11/2020. [Online]. Available: https://jpt.spe.org/offshore-hydrogenproduction-enables-far-offshore-wind-development.
[19] World Energy Council, "Bringing North Sea energy ashore efficiently", 2017. [Online]. Available: https:// www.worldenergycouncil.nl/new-report-released-onbringing-north-sea-energy-ashore-efficiently/.

[20] Gassnova SF, "UK's hydrogen strategy proposal launched", 2021.

[21] Northern Lights, "About the longship project", 2021. [Online]. Available: https://northernlightsccs.com/ about-the-longship-project/.

[22] Norwegian Government, "The Government launches 'longship' for carbon capture and storage in Norway", 21/9/2020. [Online]. Available: https://www. regjeringen.no/en/aktuelt/the-government-launcheslongship-for-carbon-capture-and-storage-in-norway/ id2765288/.

[23] Equinor, "Carbon capture, utilisation and storage (CCS \& CCUS): We're sending carbon back where it came from", 2021. [Online]. Available: https://www.equinor. com/en/what-we-do/carbon-capture-and-storage.html.

[24] Gassnova SF, "Developing longship, key lessons learned", 25/11/2020. [Online]. Available: https:// gassnova.no/en/news/report-developing-longship-keylessons-learned.

[25] North Sea Energy, "JVERGAS: Feasibility of hydrogen generation on a multifunctional island at IJmuiden Ver", 2020.

[26] Nexstep, "Offshore decom conference: National platform for re-use \& decommissioning", 2017.

[27] Nguyễn Thu Hương, "Báo cáo khảo sát: Tận thu giá trị các tài sản khai thác dâu khí ngoài khơi sau khi dựán dừng hoạt động", Viện Dầu khí Việt Nam, 2021.

[28] Viện Năng lượng, "Dự thảo Đề án Quy hoạch phát triển điện lực quốc gia thời kỳ 2021 - 2030, tâm nhìn đến năm 2045", 2021. 